\title{
Supercapitalismo na relação entre o licenciamento ambiental e o financiamento de campanhas eleitorais
}

\author{
Supercapitalism in the relation between the environmental \\ licensing and the financing of electoral campaigns
}

Alexandre Cosme José Jeronymo

${ }^{a}$ Doutor em Energia pela UFABC, colaborador do Instituto Brasileiro de Estudos Contemporâneos, São Paulo, SP, Brasil End. eletrônico: alexandrecjj@gmail.com

doi:10.18472/SustDeb.v8n2.2017.20433

Recebido em 09.11.2016

Aceito em 25.05.2017

ARTIGO - VARIA

\section{RESUMO}

O artigo estabelece aproximações entre os limites do licenciamento ambiental e os financiamentos corporativos para campanhas políticas eleitorais. A ocorrência desta aproximação cria um ambiente denominado Supercapitalismo, que é permissivo para converter o território da democracia ambiental no território dos grupos econômicos que capturam a classe política. Essa correlação envolve a doação-empréstimo de dinheiro para campanhas políticas e a sua evolução reside na captura do Estado pelos agentes econômicos. Os mecanismos utilizados para recuperar a doação-empréstimo instrumentalizam o Estado e o licenciamento ambiental. A construção do artigo considera indicadores de desconfiança na classe política e nos partidos políticos, utiliza trabalhos acadêmicos, pesquisas de organizações não governamentais e informações da imprensa quando revelam episódios de estudos de impactos incompletos, deslocamentos populacionais e indenizações irrisórias, e audiências públicas fraudulentas. $O$ artigo conclui indicando que a doação-empréstimo ingressa na política, na classe política, instrumentaliza o Estado e corrompe processos que intencionam a democracia ambiental.

Palavras-chave: Supercapitalismo; Financiamento de Campanhas Eleitorais; Democracia Limitada; Licenciamento Ambiental.

\section{ABSTRACT}

The paper establish approximations between the limits environmental licensing and corporate financing for electoral political campaigns. The occurence this aproximation create the environment called Supercapitalism, which is permissive to convert the territory of environmental democracy into territory of economic groups and political class captured. This correlation involves the donationloan of money for the campaign politics and its evolution to fix residence in the capture of State by economics groups. The mechanisms used for the recuperation of the donation-loan instrumentalize the environmental licensing public authorities. The construction of the paper consider indicators of distrust in the political class and political party, use academic work, studies of nongovernmental organizations, 
and information of the press when reveal episode of the incompletes environmental impacts studies, population displacement and indemnification derisory, and fraudulent public hearings. Concludes signaling that the donation-load entered politics, captures the political class, instrument the State and corrupt process that environmental licensing and environmental democracy.

Keywords: Supercapitalism; Election Campaign Financing; Limited Democracy; Environmental Licensing.

\section{INTRODUÇÃO}

O licenciamento ambiental brasileiro é um dos instrumentos da Política Nacional do Meio Ambiente (PNMA) e uma obrigação prévia para todo empreendimento com potencial para produzir impactos. São muitos e variados os interesses e disputas que envolvem o licenciamento ambiental e, não é incomum, identificar o instrumento como estático. "Há muitos exemplos de legislações repletas de anacronismo, mesmo que tenham sido escritas com justas intenções, como a tributária, a trabalhista, a ambiental" (GODOY, 2009, p. 2).

Nesse sentido, os estudos do Instituto Acende Brasil (2014) enfatizam que a principal razão para atrasar a implantação de empreendimento é a característica ampla, complexa, incerta, imprevisível e passível de contestação do licenciamento ambiental; situações que (INSTITUTO ACENDE BRASIL, 2011) representam maior custo socioambiental, variando entre 1,1\% e 5,4\%, segundo análise de processos de 25 usinas hidrelétricas licenciadas pelo Instituto Brasileiro de Meio Ambiente e Recursos Renováveis (Ibama).

Por outro lado, a literatura reconhece que as construções hidrelétricas provocaram múltiplos impactos sociais, ambientais e econômicos. A crítica de Zhouri, Laschesfiki e Paiva (2014, p. 99) aponta que "a legislação tem sido reinterpretada, casuisticamente, em especial quando entendida como obstáculo ou quando se apresenta contrária ao modelo desenvolvimentista e aos interesses vorazes do mercado", e Laschefski (2011, p. 50) defende que as flexibilizações do licenciamento ambiental não atuam na efetiva democratização do desenvolvimento e diminuem as poucas e eficientes participação popular.

Para Bermann (2007, p. 142), as usinas hidrelétricas construídas até hoje no Brasil expulsaram cerca de 200 mil famílias ribeirinhas diretamente atingidas; o processo de reassentamento, quando houve, não assegurou a manutenção das condições de vida anteriormente existentes, e com frequência representou a destruição de seus projetos de vida. As interpretações sobre as potencialidades e os limites do licenciamento ambiental são amplas e contrapostas.

Diante do quadro exposto, este trabalho está apoiado na concepção e construção do Supercapitalismo, de acordo com Richard Reich. A dinâmica do Supercapitalismo é permissiva à conversão do território da democracia e da resolução das demandas sociais, no território do acolhimento das demandas de determinados grupos econômicos e dos interesses privados. As etapas que intencionam construir o ambiente democrático, nas diferentes instâncias do Estado, podem sofrer constrangimentos e compor processos avessos à prática democrática. Esse caráter do Supercapitalismo corrói os órgãos e instituições públicas, manipula legislações e incentiva a produção da desconfiança social na classe política e no sistema político. É defendido que a recuperação da doação-empréstimo instrumentaliza o Estado, desconstrói o licenciamento ambiental e fragiliza a democracia ambiental.

A construção deste trabalho considera pesquisas e estudos acadêmicos sobre a desconfiança na classe política e nos partidos políticos. Para recorrer ao Supercapitalismo o trabalho identifica nos limites do licenciamento ambiental as correlações com a enxurrada de dinheiro corporativo (doaçãoempréstimo) que ingressa nas campanhas políticas eleitorais. O circuito da doação-empréstimo é concluído com a instrumentalização das etapas do processo de licenciamento ambiental. Estudos e pesquisas de organizações não governamentais, trabalhos acadêmicos e informações da imprensa são utilizados para revelar a conclusão do circuito doação-empréstimo no formato de estudos de impactos incompletos e deferidos pelos órgãos ambientais responsáveis, pelos deslocamentos populacionais e indenizações irrisórias, pelas audiências públicas fraudulentas. 


\section{A POLÍTICA NACIONAL DE MEIO AMBIENTE NO BRASIL E O LICENCIAMENTO AMBIENTAL}

Ações que representam a preocupação ambiental no Brasil ocorreram durante os períodos colonial e imperial, e ao longo do século XX. A Lei no 6.938/1981, a responsável pela política nacional de meio ambiente no Brasil, aperfeiçoa o tratamento dos assuntos ambientais.

A Política Nacional de Meio Ambiente (PNMA) constituiu o Sistema Nacional de Meio Ambiente (Sisnama) e criou o Conselho Nacional de Meio Ambiente (Conama). A resolução Conama definiu o licenciamento ambiental como:

Procedimento administrativo pelo qual o órgão ambiental competente licencia a localização, instalação, ampliação e a operação de empreendimentos e atividades utilizadoras de recursos ambientais, consideradas efetiva ou potencialmente poluidoras; ou aquelas que, sob qualquer forma, possam causar degradação ambiental, considerando as disposições legais e regulamentares e as normas técnicas aplicáveis ao caso (CONSELHO NACIONAL DE MEIO AMBIENTE, 1997).

Os procedimentos para aprovar o Estudo de Impacto Ambiental (EIA) exigem do agente econômico os deferimentos das licenças ambientais (prévia, instalação e operação). O contexto da obtenção dessas licenças envolve conflitos e disputas entre as diferentes formas de apropriação e uso do meio ambiente. Existem objetivos orientados para a reprodução social, cultural e econômica, e outros que utilizam o meio ambiente como insumo industrial e depósito de resíduos.

Independente da condição conflituosa o licenciamento ambiental pode ser corrompido e ter obstruída a intenção democrática. As audiências públicas, o sistema judiciário e a própria legislação podem sofrer cooptações e conversões dos processos democráticos em decisões instrumentalizadas, isto é, em virtude do atendimento dos interesses políticos, dos agentes econômicos e de setores da economia em colaboração conjunta.

\section{A DEMOCRACIA ACABRUNHADA}

Na esteira dos obstáculos que fragilizam a PNMA está a enxurrada de dinheiro que ingressa nas campanhas políticas eleitorais, e a conversão do território da democracia, dos direitos e dos deveres, no território da democracia acabrunhada e do dinheiro.

No trabalho de Reich $(2005$, p. 5), a democracia acabrunhada tem origem no fortalecimento e expansão do capitalismo nos EUA, na ampliação e variedade dos produtos, nas maiores oportunidades de a população norte-americana agir como consumidora e investidora e, simultaneamente, o contraste desse ambiente é a perda do terreno da cidadania política, dos direitos sociais e humanos, e o declínio das instituições responsáveis pela proteção do bem comum. Quando é maior a oferta de bens e serviços a condição consumidora é beneficiada e fortalecida, mas, inversamente, a cidadania e os direitos são enfraquecidos.

Esse processo envolve as competições empresariais, as cadeias globais, as inovações e produz o que "eu denomino como Supercapitalismo" (REICH, 2008, p. 5), algo que é particular do próprio capitalismo quando refina as suas sensibilidades para atender os desejos dos potenciais consumidores. $\mathrm{Na}$ concepção de Dowbor (2009, p. 1), esse caráter tentacular do "Supercapitalismo é simplesmente o vale-tudo econômico e financeiro que se instalou no quadro que temos chamado de globalização".

No Supercapitalismo as instituições e organizações concebidas no bojo social entram em crise. Para Reich (2008), é o caso dos sindicatos trabalhistas que encolheram, as agências reguladoras incumbidas de zelar pelo bem comum se atrofiaram, o serviço público eleito passou a se preocupar menos com os cidadãos e com as comunidades e a interessar-se mais em atrair dinheiro para as suas campanhas, os governos com representação comunitária entraram em processo de extinção, grupos de interesses locais reivindicam cada vez menos a atenção dos legisladores. 
Simultaneamente, no Supercapitalismo há o fortalecimento da dinâmica econômica e o atendimento dos consumidores quando oferece melhores ofertas, preços e diversidades no mercado (REICH, 2008).

Em contraposição, o Estado, quando implementa políticas ambientais e de condições de trabalho decente, é signatário dos tratados internacionais para diminuir poluição e degradação ambientais, e fiscaliza o desenvolvimento dessas ações. O resultado imediato pode envolver o aumento no custo do processo produtivo e, por extensão, as limitações para ofertar os melhores preços, conquistar e reter consumidores.

Na interpretação de Wooldridge (2012, p. 122), o Supercapitalismo não é impulsionado pelos burocratas sem rosto, mas por você e eu, e isso pelo fato de os consumidores exercerem uma pressão implacável sobre as empresas para que elas melhorem sua qualidade e cortem os seus custos. Quando a empresa traça planos, estratégias, cenários, e busca mecanismos para oferecer melhores produtos, serviços e preços, embora a intenção seja o atendimento do consumidor, o resultado fortalece a competição e pode desenvolver finos e obscuros mecanismos em virtude do benefício empresarial.

A competição entre setores da economia e/ou agentes econômicos é incentivada pela "enxurrada de dinheiro das empresas que inunda a política" (REICH, 2005, p. 144) e as campanhas eleitorais. 0 objetivo é capturar o agente político (a classe política eleita) e manipular o Estado para beneficiar agentes econômicos que podem atuar em blocos organizados, e também isolados. Na competição empresarial os adversários desenvolvem estratégias para atender às demandas e ampliar o mercado consumidor. Quando o agente econômico oferece dinheiro para a classe política, os seus concorrentes tendencialmente reproduzirão o ato.

O resultado é a limitação da democracia e as insatisfações sociais. "Nossas vozes como cidadãos em contraste com nossas vozes como consumidores e investidores - estão sendo abafadas [...]. 0 Supercapitalismo transbordou para a política, engolfou a democracia" (REICH, 2005, p. 167). As necessidades mais urgentes das populações, e as diversidades, formas e usos sociais do meio ambiente perdem a prioridade. A pressão exercida pelos agentes econômicos diante do Estado é econômica e política.

A análise de Sevá aponta os agentes públicos e privados, e as instituições criando uma engenharia política que pode limitar o ambiente democrático em virtude da realização dos projetos de infraestruturas e dos objetivos econômicos e políticos.

\footnotetext{
Mobilizar recursos financeiros dessa ordem resulta de uma estratégia também muito peculiar: cada projeto tem que ser criado como uma árvore, "tornado irreversível", reduzindo o risco, identificando os resistentes e conseguindo dobrá-los... ou eliminá-los. Para tanto, costurar apoio em várias instâncias, desde o local onde estão os grupos atingidos, os vizinhos, os jornais e rádios, até os níveis do prefeito, dos governadores. Muita coisa se explica pelas relações estreitas e às vezes secretas entre os executivos e gerentes das corporações e - os homens da Administração: os funcionários e togados da Justiça, os agentes do Fisco, das Aduanas, dos Serviços e Obras Públicas, das agências ambientais e trabalhistas - e - os eleitos dos Parlamentos. Toda essa engenharia política é proporcional ao enorme volume que vai ser desembolsado; um avanço de capital da ordem de 10, 20 bilhões de reais, que só pode ser reembolsado muitos anos depois, amarra todo o sistema e a sociedade local e regional em função do pagamento desse empréstimo (SEVÁ, 2011, p. 67).
}

As dinâmicas produzidas pela relação entre o agente econômico e o agente público revelam o interesse corporativo, e a captura da representação política eleita pelo voto popular e o aprisionamento do Estado.

Ao capturar a representação política, há o exercício da influência assimétrica de determinados agentes econômicos em detrimento de outros, das empresas privadas ou entidades representativas de setores da economia sobre os processos ou instâncias decisórias, e muitas vezes em prejuízo do interesse público (BERRÓN, GONZÁLEZ, 2016, p. 16) e corrobora com as instrumentalizações da democracia, das legislações e da representação política eleita pelo voto direto. 


\section{DOAÇÃO-EMPRÉSTIMO PARA A CLASSE POLÍTICA}

A Lei no 9.504/97 instituiu o financiamento de candidatos e campanhas eleitorais no Estado brasileiro. Essa lei incentiva o debate com argumentos pró e contra o financiamento. Por um lado, os defensores do financiamento destacam que a contribuição empresarial para partidos e candidatos contribui para o processo democrático, corrobora com a solidez dos partidos políticos, e o fortalecimento dos partidos no ambiente da democracia moderna (INSTITUTO ETHOS, 2014, p. 55).

É reconhecida a importância do dinheiro para o bom funcionamento da democracia, para estabelecer organizações partidárias sustentáveis e proporcionar a oportunidade de competição partidária em termos iguais (FALGUERA, 2011).

Por outro lado, em muitos aspectos, "as doações privadas para as campanhas seguem uma lógica de mercado" (INSTITUTO ETHOS, 2014, p. 28) e podem proporcionar aos agentes econômicos a conquista do "poder de influência sobre os governantes e, principalmente, conquistar mais poder do que suas concorrentes é assunto de importância estratégica" (ABRAMO, 2014, p. 2). O financiamento é um problema quando os partidos e os candidatos têm oportunidades desiguais para acessar fundos, embora a popularidade possa produzir níveis variados de apoio financeiro (FALGUERA, 2011, p. 348). No caso brasileiro, "temos a apropriação de políticos através do financiamento privado das campanhas, e a monopolização da agenda do Congresso e do Executivo pelos lobbies dos grandes grupos empresariais" (DOWBOR, 2009, p. 1) como as bancadas de empreiteiros e construtoras, a empresarial, a agropecuária, a evangélica, da bala (empresas de segurança), da saúde, da mineração, e dos direitos humanos. Não pode ser desprezada a doação decorrente das compatibilidades ideológicas entre quem faz a doação e quem a recepciona.

A literatura reconhece que os candidatos que mais gastam em campanhas políticas são os eleitos. A correlação significa: pouco importa o projeto político, mas é necessário que o candidato disponibilize dinheiro para a campanha política. Essa situação reorienta a arena política quando privilegia a relação entre a classe política e os agentes econômicos financiadores, e coloca em detrimento a conexão entre o projeto político e a sociedade.

A irrigação de dinheiro nas disputas eleitorais brasileiras é exponencial. As doações empresariais são dirigidas para os candidatos, os diretórios dos partidos políticos e os Comitês Eleitorais. A fonte pública é o fundo partidário e as propagandas políticas gratuitas nas emissoras de rádio e televisão. Números do Tribunal Superior Eleitoral (TSE) apresentam o quanto de dinheiro ingressou nas campanhas políticas.

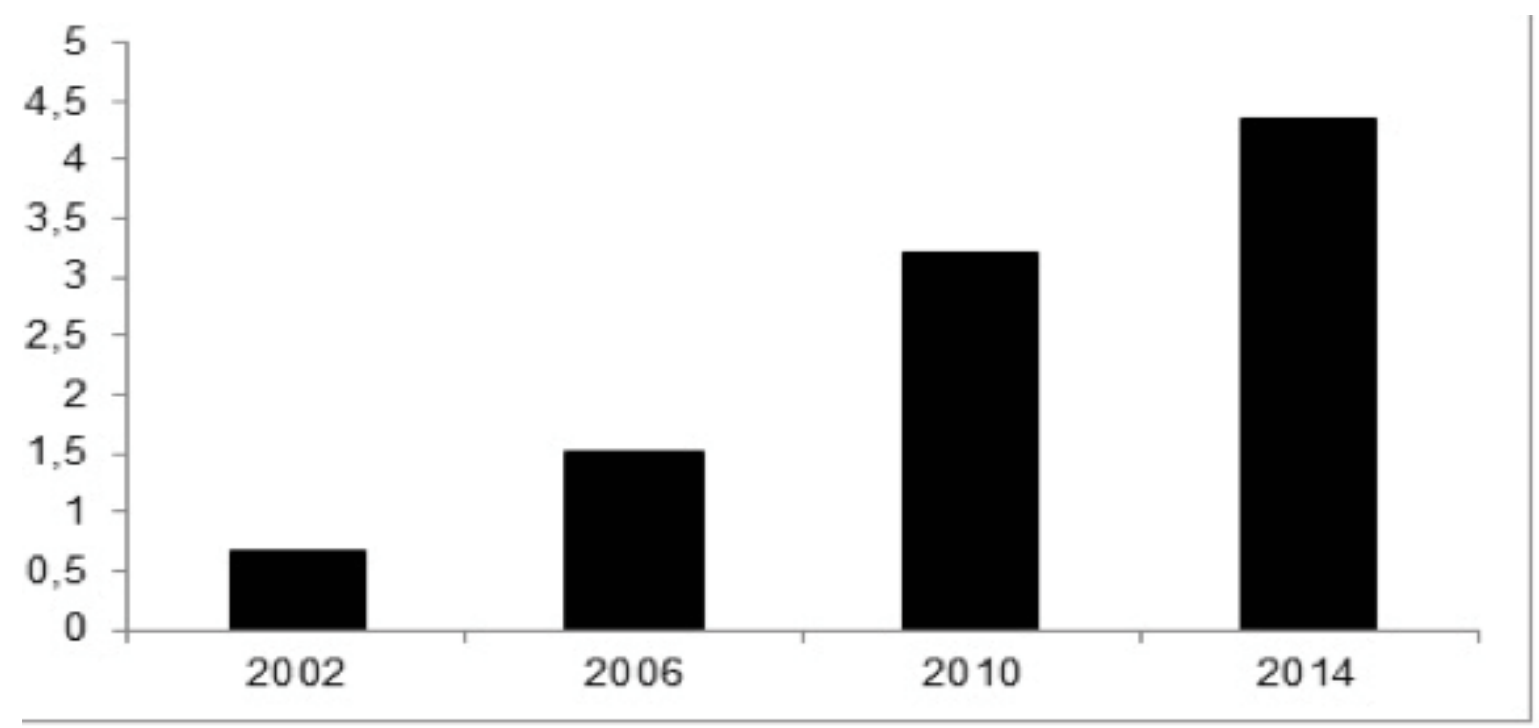

Figura 1 - Valores arrecadados pelas candidaturas, em bilhões de R\$.

Fonte: Tribunal Superior Eleitoral (2002, 2006, 2010, 2014). 
A Figura 1 é representativa para pensar a irrigação de dinheiro influenciando e decidindo sobre temas variados, e para refletir sobre o comportamento do Estado, da política e da democracia.

Os Comitês Financeiros/Diretórios têm a missão de arrecadar recursos econômicos para as campanhas. O conjunto dos valores arrecadados pelos Comitês/Diretórios é assim identificado.

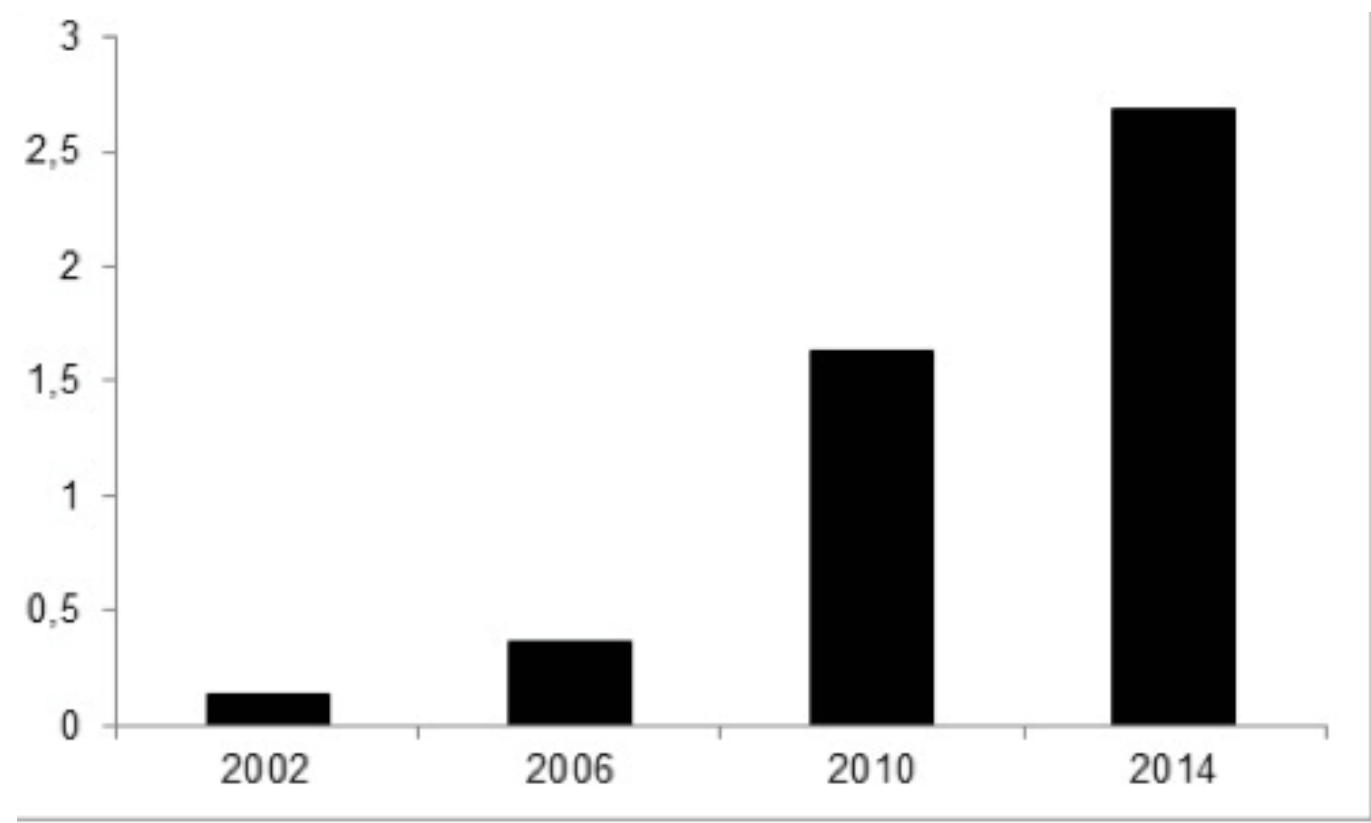

Figura 2 - Valores arrecadados pelo Comitê Financeiro/Diretório Nacional do Partido, em bilhões de R\$.

Fonte: Tribunal Superior Eleitoral (2002, 2006, 2010, 2014).

Para a eleição de 2014 as doações-empréstimos direcionadas para os partidos políticos foram estratificadas pela organização não governamental "Às Claras", a partir dos dados do TSE.

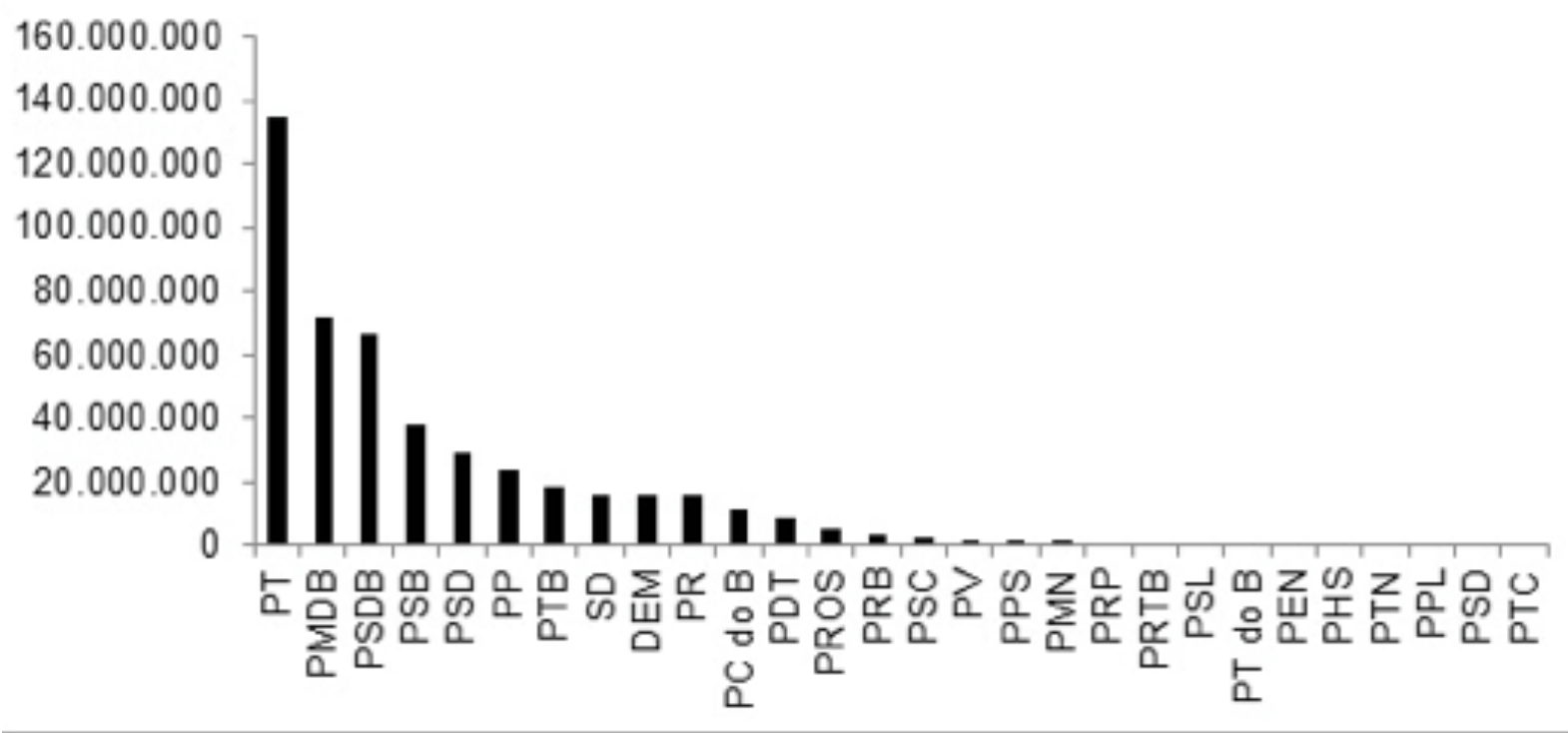

Figura 3 - Valores arrecadados por cada partido político, em milhões de $\mathrm{R} \$$.

Fonte: Às Claras, 2014, apud Abramo (2014). 
Chama atenção o volume de dinheiro dedicado para o PT, o PMDB e o PSDB. São valores que contrastam com a quantidade de dinheiro que ingressou nos chamados partidos nanicos, como o PTC, PSD e PPL. Isso mostra que as doações não são uniformes, ou seja, o processo que estratifica o volume de recursos econômicos que ingressa na política define os partidos merecedores do dinheiro privado e da confiança política do agente econômico. Irrigar com dinheiro os partidos políticos, as principais siglas e as nanicas mostra o pragmatismo corporativo empresarial.

O setor da construção foi um dos principais doadores na eleição presidencial de 2014, e o padrão de comportamento das construtoras revela a doação para os quatro principais partidos (PT, PMDB, PSDB e PSB) e as diferentes estratégias.

\begin{abstract}
A OAS e a Andrade Gutierrez dedicaram cerca de metade dos recursos para o PT. No caso da OAS, o restante foi dividido em partes ligeiramente decrescentes entre PMDB, PSDB, PSB. Já a Andrade Gutierrez aquinhoou o PSDB com a segunda maior parcela, mas o PMDB e o PSDB ficaram com montantes bem menores. A UTC Engenharia, por sua vez, apostou mais de $70 \%$ de suas fichas para o setor no PT e o restante foi dividido, outra vez em partes decrescentes entre os três demais partidos. A Odebrecht, de seu lado, tratou PT e PSDB de forma semelhante, o mesmo acontecendo com PMDB e PSDB. A Queiroz Galvão, por fim, agradou em partes iguais ao PT, ao PSDB e ao PMDB, dedicando ao PSB menos de $10 \%$ do total que doou ao conjunto dos quatro partidos (ABRAMO, 2014, p. 3).
\end{abstract}

As estratégias evidenciam que as doações privilegiam o PT e o PSDB, e entre esses é o PT o maior beneficiado pelo fato de ocupar o governo. No Brasil as empreiteiras financiam campanhas políticas para garantir que os seus interesses sejam atendidos pelo Legislativo e pelo Executivo (BERRÓN, GONZÁLEZ, 2016 , p. 16) e nutrem a expectativa que é a elaboração de mecanismos para atender as próprias demandas, e subtrair processos potencialmente prejudiciais para o setor e agentes econômicos.

No ambiente político acabrunhado a recuperação da doação-empréstimo corrói a democracia e contribui para reduzir a confiança nas instituições e nos partidos políticos.

A pesquisa da Corporación Latinobarómetro, entre os anos 1995 e 2015, aponta que a cidadania brasileira reduziu a confiança no governo. A cidadania que conferia muita confiança no governo declinou de $13,4 \%$ (em 1995) para 3,1\% (em 2015), e a cidadania que conferia nenhuma confiança aumentou de 32,8\% (em 1995) para 42,1\% (em 2015) (CORPORACIÓN LATINOBARÓMETRO, 2015). A desconfiança cidadã no governo aumentou.

A confiança nos partidos políticos brasileiros declinou entre os anos 1995 e 2015. No estudo do Latinobarómetro (2015), para a cidadania que depositava muita confiança nos partidos políticos a queda foi de 4,7\% (em 1995) para 1\% (em 2015), e quem depositava algo de confiança foi surpreendido pela queda de $12,3 \%$ (em 1995) para $9,1 \%$ (em 2015), e a cidadania que depositava pouca confiança oscilou entre $32,4 \%$ (em 1995) e $36,1 \%$ (em 2015), e para aqueles que não confiam nos partidos políticos ocorreu o aumento de 48,1\% (em 1995) para 51,4\% (em 2015).

Em pesquisa realizada pelo Instituto Brasileiro de Opinião Pública e Estatística (2013), entre os anos 2009 e 2013, o índice de confiança social nas instituições declina de 58\% (em 2009) para 47\% (em 2013), e quando o assunto é o partido político a queda é de $31 \%$ para $25 \%$.

Em linhas gerais, a desconfiança no governo e as insatisfações sociais com os partidos políticos ilustram o descontentamento do cidadão com a representação política brasileira. Ao financiar campanhas eleitorais os agentes econômicos iniciam a captura dos agentes políticos e do Estado, posteriormente efetuam a recuperação dos investimentos quando o Legislativo, Executivo e Judiciário atendem às demandas corporativas.

A doação-empréstimo é um mecanismo de corrosão do ambiente democrático e contribui decisivamente para aumentar a desconfiança cidadã no governo, nos partidos políticos e na classe política. Está no conjunto dos resultados o constrangimento da democracia e dos seus processos, e isso em virtude da recuperação do dinheiro emprestado pelos agentes econômicos. 


\section{RECUPERANDO A DOAÇÃO-EMPRÉSTIMO}

Quando o Estado cria e executa os mecanismos orientados para a promoção do desenvolvimento respeitando as sociedades e o meio ambiente, fiscalizando e punindo os agentes econômicos que impactam o meio ambiente, os fundamentos e conteúdos democráticos são respeitados e ajustados. Em contrapartida, quando o aparato jurídico-ambiental e a fiscalização dos agentes poluidores são limitados - pelas ausências de profissionais capacitados, de infraestruturas, e pela ocorrência de fraudes -, os elementos democráticos perdem os valores correspondentes.

Para ocorrer a recuperação da doação-empréstimo as estratégias que constrangem o ambiente democrático e as legislações são acionadas. Os mecanismos para desenvolver e concluir o circuito da doação-empréstimo envolvem a redação e aprovação de leis e decretos, publicação de editais parceiros, conhecimento antecipado e informação privilegiada, organização de bancadas parlamentares orientadas para atacar e defender projetos, e emendas organizadas no ambiente privado e para objetivos privados.

No caso do setor da construção civil, em particular os projetos hidrelétricos, o percurso para recuperar a doação-empréstimo envolve a invisibilização das famílias e grupos sociais na área de influência e a desconstrução da aparelhagem jurídico-ambiental. Os temas que envolvem a sociedade e as suas formas de vida e de identificação territorial, as audiências públicas e as discussões coletivas com proprietários de terras inclusas nas áreas de influência do projeto, os reassentamentos para as populações atingidas e as indenizações são obrigações que o agente econômico necessita responder para obter as licenças ambientais e prosseguir com investimentos. Entretanto, o atendimento das determinações legais com frequência oscila entre o parcial e o integral.

\subsection{RECUPERAÇÃO DA DOAÇÃO-EMPRÉSTIMO E OS ESTUDOS DE IMPACTOS AMBIENTAIS INCOMPLETOS (EIAS)}

É obrigação de o agente econômico apresentar EIA para licenciar as atividades modificadoras do meio ambiente. É certo que o agente econômico não irá produzir ou contratar consultoria ambiental para realizar o EIA e não obter os licenciamentos ambientais necessários para os próprios projetos. Isto significa dizer que o EIA precisa das licenças deferidas, mas não significa que o projeto licenciado estará respondendo pela qualidade que necessita demonstrar.

Para Laschefski, Paiva, Zhouri (2014, p. 103), o vínculo entre o empreendedor e a consultoria ambiental insere-se na lógica de mercado, ou seja, o EIA é uma mercadoria que será adquirida pelo empreendedor, que objetiva aprová-lo pelos órgãos licenciadores. O processo que configura o deferimento produz características onde, por um lado, o agente econômico transita por entre as próprias atividades, a consultoria ambiental e as instituições públicas responsáveis pelo licenciamento, e assim o faz para subtrair a possibilidade que é o indeferimento do projeto em análise. Por outro lado, e simultaneamente, no trânsito do agente econômico permanece a estratégia que é a instrumentalização dos pareceres e o deferimento do licenciamento. A pressão e o constrangimento do servidor público lotado nas instituições responsáveis pela análise dos projetos são mecanismos utilizados para acelerar as análises e entregar licenças deferidas.

Os servidores técnicos do Ibama, por exemplo, foram pressionados para acelerar a concessão de licenças ambientais. Hernandez e Magalhães (2011, p. 92) relatam que o ex-coordenador-geral de Infraestrutura de Energia Elétrica do Ibama, Leozildo Tabajara da Silva Amorim, e o diretor de Licenciamento, Sebastião Custódio Pires, pediram demissão após uma reunião em que o então ministro do Meio Ambiente, Carlos Minc, tentou ensinar os analistas ambientais do Instituto a fazer licenciamento.

Os pesquisadores Hernandez e Magalhães (2011, p. 92) destacam a pressão jurídica e a intimidação exercidas pela Advogacia Geral da União (AGU), ao perseguirem procuradores e juízes que disparam ações civis públicas e concedem liminares contra projetos e processos governamentais. 
O Conselho de Defesa de Direitos da Pessoa Humana (2010) recebeu denúncias de violação dos direitos humanos em 74 usinas hidrelétricas (em fase de licenciamento, implantação e operação) nas cinco regiões do país, e denuncia a limitada orientação jurídica das populações atingidas.

\begin{abstract}
A rapidez na cassação de liminares favoráveis a atingidos e na concessão de interditos proibitórios em favor das empresas tem como contraface a lentidão e os artifícios protelatórios quando são questionadas ações das empresas - de que são prova reiterada os processos em que se questiona valores de indenizações, para citar um exemplo (CONSELHO DE DEFESA DOS DIREITOS DA PESSOA HUMANA, 2011, p. 22).
\end{abstract}

A pressão exercida contra os servidores do Ibama, pela AGU, e a revelação do Conselho de Defesa de Direitos da Pessoa Humana são diferentes formas de intimidar, amedrontar, interferir politicamente nos deferimentos e indeferimentos das análises dos EIAs, e de instrumentalizar instituições e agentes públicos em virtude da realização de interesses de grupos.

O livro "A hidrelétrica que não viu a floresta" reúne inconsistências, deficiências e os vícios do licenciamento ambiental do EIA da Usina Hidrelétrica de Energia (UHE) de Barra Grande, no Rio Pelotas. Para Zen (2005, p. 32), o EIA baseou-se em informações fraudulentas ao ignorar matas virgens e florestas em estágio avançado de regeneração, e o lbama alegou que a obra não traria graves prejuízos a bens ambientais protegidos pela legislação. Segundo Prochnow (2005, p. 39), as araucárias cortadas "são em sua absoluta maioria, centenárias, com tronco cilíndrico e reto, portanto, darão madeira considerada de primeira qualidade", e os custos ambientais diretos "não incluem o valor intrínseco da biodiversidade e os serviços ambientais da floresta, os quais são incalculáveis, ainda mais se tratando das áreas de maior diversidade genética de araucária em Santa Catarina".

O exemplo da UHE Barra Grande não é isolado quando o assunto é a subtração de infraestrutura e as áreas ambientalmente relevantes. É o método utilizado pelo agente econômico para viabilizar a redução dos custos ao inviabilizar o ambiente e infraestruturas, e subtrair os diferentes usos e apropriações que a diversidade social faz do meio ambiente. A invisibilização está entrelaçada com os mecanismos que preveem redução dos custos para instalação dos empreendimentos (JERONYMO; BERMANN; GUERRA, 2012, p. 187), e o mecanismo em questão poderá subtrair o período para a realização da recuperação doação-empréstimo.

A existência de EIA deficiente pode ser confundida com a negligência e a má-fé. Porém, no Supercapitalismo, com capturas dos agentes políticos e do Estado, o EIA que não cumpre com a sua finalidade, subtrai as atividades antrópicas, infraestruturas e as diferentes formas de subsistência e uso dos recursos, corrobora com a invisibilização e dialoga com a premeditação. Não há negligência e máfé. São métodos, procedimentos, formas de ação, convencimento e pressão.

\title{
5.2 RECUPERAÇÃO DA DOAÇÃO-EMPRÉSTIMO E AS AUDIÊNCIAS PÚBLICAS
}

A audiência pública é o principal canal de comunicação entre o agente econômico e a sociedade, e está institucionalizada pela Resolução do Conama no 9/1987.

O ambiente da audiência pública intenciona informar e ser informado, para a participação social exigir complementações, modificações e recusar o projeto. A formalização desse espaço, por si só, não cumpre o fortalecimento do processo democrático, pode ignorar práticas viciadas e comprometer a construção da política ambiental democrática.

Em muitos casos, os empreendedores organizam "reuniões informativas", onde só eles dão explicações e batizam o evento, de modo abusivo, irregular, como "Audiência Pública". Mesmo lá onde foram feitas Audiências conforme o ritual, isso pouco influiu nas decisões políticas já combinadas; p.ex. as usinas hidrelétricas do Lajeado, no Tocantins, e de Corumbá IV, em Goiás (SEVÁ, 2004, p. 11).

Hernandez e Magalhães (2011, p. 88-89) analisaram as longas audiências públicas da UHE Belo Monte, e foi verificado nas três primeiras audiências que o debate substantivo ficou restrito às poucas pessoas que permaneceram no local por pelo menos seis horas, e que na prática reuniu pessoas com convicções mais fortes sobre o projeto; e, cabe relatar, que houve tentativa de manobrar, com o intuito em negar a participação social na audiência pública, a partir da proposta de selecionar os seus participantes. 
Baraúna e Marin (2011, p. 104) descrevem que a audiência pública da UHE de Jirau parecia estar ocorrendo apenas para cumprir o que estava na resolução Conama, e era controlada pelos monitores da audiência pública (Ibama, Enersus) e não mostrava ser tão democrática quanto se pensava.

A audiência pública realizada pelo Consórcio UHE Candonga, conforme descrição das entidades Centro de Justiça Global, Comissão Pastoral da Terra, Movimento dos Atingidos por Barragens, Núcleo de Assessoria às Comunidades Atingidas por Barragens (2004, p. 30), lotou a igreja central de representantes do Consórcio, do Estado, da prefeitura e membros da comunidade, e a explanação utilizou o recurso do tecnicismo que afastou a capacidade de compreensão e de participação das pessoas e, ao final, a percepção popular foi que a audiência foi convenientemente organizada para selar um acordo entre as autoridades municipais e o Consórcio e não para ouvir as dúvidas e sugestões da população.

A instrumentalização da audiência pública é intensificada quando as populações atingidas e os grupos forasteiros - pagos para ocupar o espaço da audiência e forjar o apoio social local - disputam o espaço e o ambiente da audiência. A composição social dos denominados forasteiros é destacada pela condição de desconhecerem os valores, costumes, hábitos, pessoas, e de serem estranhos ao conjunto de cidade(es) identificada(s) como área apta para o projeto. Quem conhece, reconhece-se e estabelece seus vínculos sociais, culturais, econômicos e familiares na área de influência do projeto poderá ter o direito à participação na audiência negada. A presença forasteira ocupa o espaço da audiência, terceiriza a participação pública, incentiva a participação fraudulenta e limita o ingresso das famílias envolvidas pelo projeto.

As experiências de Sevá (2004, p. 11) atestam a presença de claques trazidas de fora da cidade, seguranças e guarda-costas contratados para proteger o prefeito, o promotor, deputados, além dos gerentes e porta-vozes dos empreendedores e elaboradores de EIA.

É fundamental permitir que os elementos correspondentes ao processo democrático componham o espaço das audiências públicas e ofereçam condições para a sociedade envolvida expor as suas observações, preocupações e convicções.

\subsection{RECUPERAÇÃO DA DOAÇÃO-EMPRÉSTIMO E AS INDENIZAÇÕES}

O processo de apropriação e indenização de propriedades em passado recente envolveu famílias camponesas distantes da concepção do valor econômico da terra, conforme as apropriações para a UHE de Sobradinho, no Rio São Francisco.

Desacostumado com o dinheiro, ainda preso virtualmente a uma economia de troca, o pequeno lavrador do sertão do São Francisco é capaz de aceitar indenizações ridículas por suas terras, principalmente porque não está acostumado à ideia de que a terra tem um grande valor específico. Sempre a utilizou comunitariamente, sem ter que pagar nada a ninguém (CARVALHO, 1980, p. 110).

Atualmente, a legislação determina que o agente econômico atenda aos procedimentos de compra das propriedades e indenizações. A inovação do decreto no 7.342 (BRASIL, 2010) é a instituição do cadastro socioeconômico para identificação, qualificação e registro público da população atingida por empreendimentos de geração de energia hidrelétrica.

O Instituto de Pesquisa Econômica Aplicada (Ipea) desenvolveu metodologia para diagnosticar a dívida social do Estado com a população atingida por barragens.

Falar em diagnóstico da dívida social com os atingidos por barragens, porém, vai além dos impactos sociais que devem ser tradados no período de elaboração dos estudos de impactos do empreendimento, pois guarda relação com macroaspectos deste, como expectativas não cumpridas em relação aos impactos no desenvolvimento regional e externalidades negativas no nível local se sobrepondo às positivas (INSTITUTO DE PESQUISA ECONÔMICA APLICADA, 2014, p. 9).

A intenção desta orientação foi reduzir o desequilíbrio da dívida social, traçar cenários futuros e identificar os limites das políticas para o atendimento das populações atingidas. 
Existe o projeto № 29/2015, apresentado no Congresso Nacional pelo deputado Nilson Leitão (2015), que institui a Política Nacional de Direitos das Populações Atingidas por Barragens.

Embora os avanços na legislação sejam evidentes, o mesmo não poderá ser confirmado quando construtoras de hidrelétricas precisam respeitar as leis.

O trabalho do Conselho de Defesa dos Direitos da Pessoa Humana permitiu chegar à seguinte conclusão:

Os estudos de caso permitiram concluir que o padrão vigente de implantação de barragens tem propiciado, de maneira recorrente, graves violações de direitos humanos, cujas consequências acabam por acentuar as já graves desigualdades sociais, traduzindo-se em situações de miséria e desestruturação social, familiar e individual (CONSELHO DE DEFESA DOS DIREITOS DA PESSOA HUMANA, 2011, p. 13).

Embora o poder público desenvolva mecanismos para responder aos problemas da dívida social do Estado com as populações atingidas e tenha projetos para dirimir os problemas dessas populações, ainda assim, cumprir integralmente a legislação implementada não é a realidade. Existe lacuna entre o implementar a legislação pelo poder público e o fazer cumprir a legislação pelo agente econômico.

A presença de representantes da justiça para fazer valer a própria legislação é ação corrente. As famílias atingidas pela construção da UHE Belo Monte recorreram ao Ministério Público para fazer os próprios direitos serem validados. Na informação de Craide (2015) o defensor público da União, Francisco Rodrigues, constata que o valor das indenizações pagas pelo Consórcio responsável pela UH Belo Monte é tão baixo que as pessoas não têm essa opção; ou ficam no reassentamento ou ficam sem nada porque a indenização não vai dar nem para comprar um terreno; e o defensor identifica famílias moradoras do local não inclusas no cadastro socioeconômico; e defende que a qualidade das moradias do reassentamento é ruim, com paredes rachando e vazamentos.

O Instituto Socioambiental $(2015$, p. 12) denunciou que as famílias atingidas pela UHE Belo Monte que aceitaram indenizações monetárias receberam valores insuficientes para a aquisição de outros imóveis urbanos, dada a vertiginosa especulação imobiliária provocada pela instalação do empreendimento. Os valores pagos pela apropriação do imóvel não acompanharam a especulação imobiliária.

No contexto da democracia formal está evidenciada a presença de aparatos jurídicos para fazer valer o direito das populações que podem ser deslocadas para construção de empreendimentos hidrelétricos. Entretanto, o que permanece estrutural é a limitação das famílias que necessitam do apoio do poder público para fiscalizar o fazer cumprir a legislação na ocorrência de indenizações irrisórias, e subtrações e interpretações equivocadas da legislação.

São histórias que remetem aos limites do recebimento das compensações e indenizações, e demonstram distância com os mecanismos para reduzir as profundas alterações nas formas e modos de vida das populações atingidas. Fica identificado o limitado interesse em fazer valer o aparato legal e institucional, e o muito interesse em defender intransigentemente a realização mais velozmente da recuperação da doação-empréstimo. São procedimentos que dialogam com as determinações do ambiente do Supercapitalismo.

\section{CONSIDERAÇÕES FINAIS}

Robert Reich (2008, xii - xiv) oferece um prefácio à edição brasileira na sua obra. O autor é enfático ao afirmar que a sociedade brasileira se defrontará com as opções sobre a sociedade almejada, e as escolhas serão feitas explicitamente ou implicitamente. Independente de como sejam as escolhas, elas são necessárias, e o ideal é que a sociedade esteja preparada. A interpretação de Reich não está incorreta e não é exagerada, afinal a enxurrada de dinheiro que ingressa na política e a captura do Estado já estão presentes na dinâmica da classe política brasileira.

Ao recorrer ao Supercapitalismo como processo para discorrer sobre a PNMA, precisamente o acabrunhamento das políticas ambientais, é possível correlacionar os ataques ao licenciamento ambiental, e os interesses privados e corporativos apressados em recuperar investimentos econômicos negociados com agentes políticos e a classe política. Essa relação inicia no formato de doações de 
recursos econômicos privados para alimentar campanhas e projetos políticos da classe política, e finaliza com a devolução desse recurso no formato de leis, decretos, licitações, regulamentações e invisibilizações.

No contexto da construção dos projetos de infraestrutura hidrelétrica, a corrosão da democracia ambiental e da aparelhagem jurídico-ambiental ocorre quando os processos correspondentes ao licenciamento ambiental são atacados com o deferimento de EIAs incompletos, analiticamente pobres e com erros; com a existência de audiências públicas fraudulentas e indenizações irrisórias; quando áreas ambientalmente relevantes e infraestruturas sociais construídas pelo poder público ou pela população em regime de mutirão são invisibilizadas pelo agente econômico e pelos órgãos ambientais de fiscalização. Nessas estratégias que representam o exercício indisfarçado de apropriação privada do Estado estão os mecanismos para completar o circuito da doação-empréstimo.

O licenciamento ambiental no Supercapitalismo é conflituoso e a democracia ambiental é sistematicamente colocada sob risco pelos atropelos produzidos pelos agentes econômicos, agentes públicos, classe política e o Estado, quando atuam para atender demandas de grupos econômicos.

O trabalho de Reich não anula a responsabilidade do consumidor na construção do Supercapitalismo. O consumidor está conectado para encontrar as melhores ofertas e promoções, e desconectado das capturas, instrumentalizações e atropelos (da legislação, das audiências e das indenizações) que promovem os agentes econômicos para oferecer preços competitivos, reter consumidores e ampliar o mercado.

Fica evidente que o interessante para o consumidor é encontrar um bom produto com um bom preço, e não importa como aconteceu a produção deste produto e quais foram os mecanismos para permitir a melhor oferta. Simultaneamente, a cidadania consumidora é ampliada para consumir e procurar bons preços, inversamente, a cidadania política é restringida pela dificuldade em fazer valer os próprios direitos e pelas orientações privadas que é portador o Estado instrumentalizado.

Ao cooptar o Estado e instrumentalizar o licenciamento ambiental está em processo a conversão dessa seara da política ambiental em espaços de ações e intenções privadas, de interesses corporativos e em detrimento das demandas com maior e menor urgência da sociedade para tender interesses mesquinhos dos agentes econômicos atuando em bloco ou individualmente.

\section{REFERÊNCIAS}

ABRAMO, C. W. As rotas das doações eleitorais. São Paulo, 2014. Disponível em: <http://excelencias.org.br/ docs/rotas.pdf>. Acesso em: mai. 2015.

BARAÚNA, G. M. Q.; MARI, R. E. O fator participativo nas audiências públicas de Jirau, Santo Antônio e Belo Monte. In.: ZHOURI, A. (Org.). As tensões do lugar: hidrelétricas, sujeitos e licenciamento ambiental. Belo Horizonte: 2011.

BERRÓN, G.; GONZALEZ, L. Introdução. In: A privatização da democracia: um catálogo da captura corporativa no Brasil. In: BERRÓN, G.; GONZALEZ, L. (Org.). São Paulo: intercâmbio, informações, estudos e pesquisas, 2016.

BRASIL. Decreto no 7.342, de 26 de outubro de 2010. Institui o cadastro socioeconômico para identificação, qualificação e registro público da população atingida por empreendimentos de geração de energia hidrelétrica [...]. Diário Oficial [da] República Federativa do Brasil, Brasília, DF, de 27 out. 2010.

BRASIL. Lei no 6.938. Dispõe sobre a Política Nacional do Meio Ambiente, seus fins e mecanismos de formulação e aplicação, e dá outras providências. Diário Oficial [da] República Federativa do Brasil, Brasília, DF, de 2 set. 1981.

BRASIL. Lei no 9.504. Estabelece as normas para as eleições. Diário Oficial [da] República Federativa do Brasil, Brasília, DF, de 1 out. 13. 1997.

CARVALHO, M. Sangue da terra: a luta armada no campo. Ed. Brasil Debates: São Paulo, 1980. 
CONSELHO DE DEFESA DOS DIREITOS DA PESSOA HUMANA. Comissão Especial dos Atingidos por Barragens. Brasília, 2011. Disponível em: <http://www.ippur.ufrj.br/images/noticias/eventos_ippur/Relatrio\%20Final\%20 CDDPH.pdf>. Acesso em: set. 2016.

CONSELHO NACIONAL DE MEIO AMBIENTE. Resolução no 9 de 3 de dezembro de 1987. Dispõe sobre a realização de Audiências Públicas no processo de licenciamento ambiental. Diário Oficial [da] República Federativa do Brasil, DF, 5 jul. 1990.

CONSELHO NACIONAL DE MEIO AMBIENTE. Resolução Conama no 237. Dispõe sobre a revisão e complementação dos procedimentos e critérios utilizados para o licenciamento ambiental. Diário Oficial [da] República Federativa do Brasil, Brasília, DF, de 22 dez. 1997.

CORPORACIÓN LATINOBARÓMETRO. Latinobarómetro análisis de datos. Santiago, 2015. Disponível em: <http:// www.latinobarometro.org/latOnline.jsp>. Acesso em: 15 set. 2016.

CRAIDE, S. Famílias que serão removidas por causa de Belo Monte recorrem à defensoria. Agência Brasil, São Paulo, 2015. Disponível em: <http://agenciabrasil.ebc.com.br/direitos-humanos/noticia/2015-03/familias-queserao-removidas-por-causa-de-belo-monte-recorrem>. Acesso em: mai. 2015.

DOWBOR, L. Supercapitalismo: a transformação da sociedade. A captura do poder pelo sistema corporativo. Crise e Oportunidades, São Paulo, 2009. Disponível em: <https://criseoportunidade.wordpress.com/2009/11/06/ supercapitalismo-a-transformacao-da-sociedade-ladislau-dowbor/>. Acesso em: set. 2016.

FALGUERA, E. Conclusions. In: INTERNATIONAL INSTITUTE FOR DEMOCRACY AND ELECTORAL ASSISTENCE. (Org.). Funding of political parties and election campaigns: a handbook on political finance. Stockholm, 2014.

GODOY, P. O Estado contra o presidente do Ibama. Newsletter Diária CanalEnergia, Rio de Janeiro, 15 jul. 2009. Disponível em: <http://www.canalenergia.com.br/zpublisher/materias/CNDPCH.asp?id=72614>. Acesso em: set. 2016.

HERNANDEZ, F. D. M.; MAGALHÃES, S. B. Ciência, cientistas e democracia desfigurada: o caso Belo Monte. Novos Cadernos NAEA, Belém do Pará, v. 14, n. 1, 2011.

INSTITUTO ACENDE BRASIL. Aprimoramentos para o setor elétrico: propostas para os candidatos (mandato: 2015 - 2018). Edição n. 13. São Paulo, 2014.

INSTITUTO ACENDE BRASIL. Licenciamento ambiental: a busca da eficiência. Edição n. 12. São Paulo, 2011.

INSTITUTO BRASILEIRO DE OPINIÃO PÚBLICA E ESTATÍSTICA. Após queda acentuada em 2013, índice de confiança social se estabiliza. São Paulo, 2013. Disponível em: <http://www.ibope.com.br/pt-br/noticias/Paginas/ Ap\%C3\%B3s-queda-acentuada-em-2013,Indice-de-Confianca-Social-se-estabiliza.aspx>. Acesso em: mai. 2015.

INSTITUTO DE PESQUISA ECONÔMICA APLICADA. Metodologia para o Diagnóstico Social, Econômico e Cultural dos Atingidos por Barragens. IPEA: Brasília, 2014.

INSTITUTO ETHOS. A responsabilidade das empresas no processo eleitoral. São Paulo, 2014.

INSTITUTO SOCIOAMBIENTAL. Dossiê Belo Monte: não há condições para a licença de operação. São Paulo, 2015.

JERONYMO, A. C. J.; BERMANN, C.; GUERRA, S. M. G. Considerações sobre a desconstrução do licenciamento ambiental brasileiro. RAEGA, Curitiba, n. 26, 2012.

JUSTIÇA GLOBAL, MOVIMENTOS DOS ATINGIDOS POR BARRAGENS, COMISSÃO PASTORAL DA TERRA, NÚCLEO DE APOIO ÀS COMUNIDADES ATINGIDAS POR BARRAGENS. Atingidos e barrados: as violações de direitos humanos na hidrelétrica Candonga. Rio de Janeiro, Ponte Nova: 2004.

LASCHEFSKI, K. Licenciamento e equidade ambiental: as racionalidades distintas de apropriação do ambiente por grupos subalternos. In: As tensões do lugar: hidrelétricas, sujeitos e licenciamento ambiental. ZHOURI, A. (Org.). Belo Horizonte: Editora UFMG, 2011. 
LEITÃO, N. Projeto de lei: política nacional de direitos da população atingida por barragens e outras providências. Brasília, 2015.

PROCHNOW, M. O crime compensa. In: Barra Grande: a hidrelétrica que não viu a floresta. PROCHNOW, M. (Org.). APREMAVI: Rio do Sul, 2005.

REICH, R. Supercapitalismo: como o capitalismo tem transformado os negócios, a democracia e o cotidiano. São Paulo: Editora Campus, 2008.

SEVÁ, O. Desfiguração do licenciamento ambiental de grandes investimentos. In: II ENCONTRO NACIONAL DA ASSOCIAÇÃO NACIONAL DE PÓS-GRADUAÇÃO E PESQUISA EM AMBIENTE E SOCIEDADE, 2004, Indaiatuba. Anais ... Indaiatuba. Disponível em: <http://www.anppas.org.br/encontro_anual/encontro2/GT/GT16/gt16_seva_filho. pdf>. Acesso em: ago. 2016.

Grandes investimentos, graves conflitos: minas, petróleo e hidrelétricas na Amazônia. In: Serviço Pastoral dos Migrantes (Org.). Seminário grandes obras e migrações. São Paulo: Serviço Pastoral dos Migrantes, 2011. Disponível em: <http://pastoraldomigrante.aracuai.net/wp-content/uploads/2011/10/LIVRO-Semin\%C3\%A1rioGrandes-Obras-e-Migra\%C3\%A7\%C3\%B5es.1.pdf>. Acesso em: 10 mai. 2017.

TRIBUNAL SUPERIOR ELEITORAL. Pesquisa de prestação de contas do candidato: eleição presidencial 2002. Brasília, 2002. Disponível em: <http://www.tse.jus.br/eleicoes/eleicoes-anteriores/eleicoes-anteriores>. Acesso em: mai. 2015.

TRIBUNAL SUPERIOR ELEITORAL. Pesquisa de prestação de contas do candidato: eleição presidencial 2006. Brasília, 2006. Disponível em: <http://www.tse.jus.br/eleicoes/eleicoes-anteriores/eleicoes-anteriores>. Acesso em: mai. 2015.

TRIBUNAL SUPERIOR ELEITORAL. Pesquisa de prestação de contas do candidato: eleição presidencial 2010. Brasília, 2010. Disponível em: <http://www.tse.jus.br/eleicoes/eleicoes-anteriores/eleicoes-anteriores>. Acesso em: mai. 2015.

TRIBUNAL SUPERIOR ELEITORAL. Pesquisa de prestação de contas do candidato: eleição presidencial 2014. Brasília, 2014. Disponível em: <http://www.tse.jus.br/eleicoes/eleicoes-anteriores/eleicoes-anteriores>. Acesso em: mai. 2015.

WOOLDRIDGE, A. Os senhores da gestão. São Paulo: Editora Campus, 2012.

ZEN, E. L. Mobilização popular tenta impedir desmatamento. In: PROCHNOW, M. (Org.). Barra Grande: a hidrelétrica que não viu a floresta. PROCHNOW, M. (Org.) Rio do Sul: APREMAVI, 2005.

ZHOURI, A.; LASCHEFSKI, K.; PAIVA, A. Uma sociologia ambiental do licenciamento ambiental: o caso das hidrelétricas em Minas Gerais. In: ZHOURI, A.; LASCHEFSKI, K.; PEREIRA, D. B. (Org.). A insustentável leveza da política ambiental: desenvolvimento e conflitos sociais. Belo Horizonte: Autêntica, 2014. 